\title{
LINKING MACRO AND MICRO THROUGH ELEMENT CYCLE: DESING RESEARCH APPROACH FOR INTRODUCTORY CHEMISTRY COURSE FOR 6-7 GRADES
}

Elena Vysotskaya, Psychological Institute of Russian Academy of Education, Moscow, Russia; h_vysotskaya@mail.ru

Svetlana Khrebtova, Moscow State Pedagogical University, Dept. of Org.Chemistry, Moscow, Russia

Iya Rekhtman Introchemist association, http://introchemist.org, Morrisville, NC, USA; iyar@introchemist.org

\begin{abstract}
To provide a solid understanding of chemistry at early stages of learning, any introductory course strives to link macro phenomena and their micro models in students' thinking through some practical work with substances and related modeling at micro level; however, the transition to elements and atoms does not get adequate consideration. Our goal is to design a teaching strategy that reveals the essence of the notion of chemical element at both levels of its representation. We assume that (1) connections between the macro and the micro can be realized if we allow students to plan the experiments, and (2) the necessary context in which the concept of chemical element really works is a problem of preparation of a certain substance from other chemicals. Upon these principles, we have developed a local instructional theory that has then been tested and revised during three long-term macro-cycles of our design research experiment in 6-7 grades. We build on the Guided Discovery Approach to teach students how to distinguish and interpret simple physical and chemical changes through the substance-based particle model. In our course, students compose and explore copper and iron cycles of transformations, model composition of particles of the substances involved, revise interpretations of the experiments, investigate displacement reactions, acids, bases, etc. without explicit references to the concept of atoms. Along this way, students realize and master the idea that elements are conserved in reactions and every element gives rise to a cycle. Atoms then emerge as units of elements. The principal advantage of this approach is the appearance of meaningful questions that the subsequent chemistry course will answer. Students acknowledge that models are revisable as needed by the experiments. Such an introduction makes the subject of chemistry much more meaningful for students and eliminates many obstacles to successful learning.
\end{abstract}

\section{Introduction}

Any introductory chemistry course strives to provide a solid understanding of the basic chemical concepts at the very early stage of learning. However, as the research literature shows, traditional approaches to teaching school chemistry often fail to serve the mission (e.g. Barke, Hazari \& Yitbarek 2009, Tsaparlis \& Sevian 2013; Franco \& Taber 2009). The complexity of the subject is due to at least two main reasons. First, it is a 'sedimentary' structure of the traditional school chemistry curriculum that 'shows inconsistent historical layers' and is seen as 'isolated from ... chemistry in society' (De Vos, Bulte, Pilot 2002, p.110). The other is a threefold nature of the subject itself: mastering the core concepts requires from 
students to move easily between three types of representation in which chemical ideas are expressed (Johnstone 2000, 2010; Gilbert \& Treagust 2009a). The first is the phenomenological type, or macro level, that represents the tangible world of substances and their numerous changes. The second is the model type, or micro level, that supports qualitative explanations of phenomena and hence involves entities that are too small to be seen directly, such as atoms, molecules, ions, etc. The third is the symbolic type that provides a quantitative explanation and thus involves symbols, formulae, equations, etc. The triplet relationship is considered as a key model for chemical education (Gilbert \& Treagust 2009; Devetak \& Glazar 2014). It is clear now that for students, the triplet relationship is difficult to understand and use because students have (a) a lack of experience with the macro type; (b) various misconceptions relating to the micro type; (c) inadequate understanding of the complex conventions at the symbolic level; (d) difficulty moving between the three levels (Gilbert \& Treagust 2009a). Under the pressure of these findings, many educators believe that in order to reconcile the instruction with the nature of learning and needs of learners, it is time to rethink what, why, and how we teach chemistry in school.

The available publications present a wide range of approaches and research projects that strive to analyze, reexam, and redesign either select topics or the entire curricula (e.g. Gilbert, De Jong, Justi, Treagust, \& Van Driel 2002; Pilot \& Bulte 2006; Gilbert \& Treagust 2009; Tsaparlis \& Sevian 2013; Devetak \& Glazar 2014; Johnson \& Papageorgiou 2010; Tsaparlis, Kolioulis \& Pappa 2010). Their findings show very clearly what necessary conditions have to be fulfilled to make the instruction more meaningful, relevant, and understandable to students, or at least more effective. These include: start teaching from the macro level; focus on meaningful learning; use active and inquiry-based forms of learning; connect teaching with everyday life to make it relevant; take into account students' alternative ideas and misconceptions; develop students' critical and creative thinking; delay introduction of chemical notation; pay special attention to the language to support the communication, and so on.

In this paper, we present a very introductory chemistry course for middle-school students (11-13 year-olds) who have never learned chemistry in formal setting. This 'first glance' at the nature of chemistry can impress students deeply enough to turn their choices toward or against the whole domain in the future (e.g. Nieswandt 2007; Johnstone 2010; Barke, Harsch \& Schmid 2012, ch.2; Vrtačnik, Sodja \& Juriševic 2014). We see our goal as to 'loosen soil' and to 'plant the seeds', and we do not expect that at this early stage students can master such important concepts of modern chemistry as isotopes, chemical bonding, oxidation numbers, mole, etc. - all this is left for a basic chemistry course for older students. However, students' understanding of 'what, why, and how' related to working with substances is our first concern, and we believe that students' ability to ask a good question has at least the same importance as to give a correct answer. 
In the following sections we outline the available approaches to designing an introductory chemistry course for middle school, the structure and main features of our course, and the benefits it brings to students and teachers.

\section{Approaches to designing an introductory chemistry course for middle school}

There is a consensus among educators about the main goals and the content of such an introductory chemistry course for lower-secondary students. The goals are (1) to familiarize students with various substances and their properties and with physical and chemical changes, and (2) to introduce the particle model of matter to form a solid basis for micro modeling in further learning. Usually, the scope includes the notions of 'molecules' (molecular species) as 'particles of a substance' and atoms as their 'blocks' (e.g. De Vos \& Verdonk 1996; Eilks 2013). It is argued that students working within a traditional curriculum face three major sources of difficulty in understanding and accepting the particle model of matter (Wiser \& Smith 2008). First, students do not have the epistemological knowledge necessary to reconcile their everyday experience with the basic tenets of the atomicmolecular theory - students know very little about the nature of scientific models and how they relate to the observed properties of objects and events. The second source is that not many students possess the macroscopic conceptions of matter, weight, volume, etc. that are necessary to support a sound understanding of the particle model. The third reason has to do with the way the atomic-molecular theory itself is taught: the information presented to students is not rich enough to make sense of the model and the language, and illustrations in textbooks are often misleading (e.g. Harrison \& Treagust 2002; Davidowitz \& Chittleborough 2009; Taber 2001; Eilks, Witteck \& Pietzner 2012).

Scientific models are not simple objects - they are tentative, designed for a special purpose, serve as a research tool to make predictions that may be tested, can evolve through an iterative process, etc. (Van Der Valk, Van Driel \& De Vos 2007). Arguably, the best way to learn the nature of scientific models is to be involved into iterative cycles of model building activity (Justi \& Gilbert 2002; Wiser \& Smith 2008).

Some recent works develop a whole learning progressions for matter. Usually, it starts with the concepts and reasoning of students entering elementary school, which is a very limited macroscopic view, and by the end, has to conform to the middle school standards regarding the atomic-molecular theory (Smith, Wiser, Anderson \& Krajcik 2006; Johnson \& Tymms 2011; Tsaparlis \& Sevian 2013, Part I). There are at least two 'big transitions' to completely new ontological levels that students should go through: the first is a transition to the basic particle model of matter (Johnson 1998), and the second is to atoms as constituent parts of pure substances - elements and compounds (Wiser \& Smith 2008; Johnson \& Papageorgiou 2010). The latter step is considered necessary to recognize, understand, and explain chemical changes just because atoms are conserved in them. However, the main focus is on the transition from the macro world to 'particles of substances' (molecules) through 
modeling activities (e.g. Lijnse, Litch, De Vos \& Waarlo 1990; Gilbert \& Treagust 2009; Tsaparlis \& Sevian 2013), while the next 'big step' from molecules to atoms and their conservation during chemical changes is often implemented according to the traditional instruction. We believe that this second transition deserves much more research attention, and the lack of students' understanding of chemical phenomena often demonstrated in the studies is due, at least partially, to the traditional way of teaching the topic.

We have been able to find only a few papers that choose different way to building with students such important concepts as chemical reaction, element, and compound. W. De Vos and A.H. Verdonk $(1985,1987)$ use the approach of guided discovery in their introductory chemistry course for 14-15 year-olds. The focus there is on the concept of chemical reaction. Initially, students perform lab experiments to find out that a new substance forms during a certain process. The authors withdraw the names and formulas of the substances, and the role of the teacher is mainly to ask a right question at the right time. An important feature of this approach is that students are allowed and encouraged 'to put their ideas into words and to compare and contrast them with their own observations of chemical phenomena' (De Vos \& Verdonk 1985, Part 1, p.238). This way, the authors encourage attempts to discover and formulate the essence of chemical change. The next and the most interesting step toward understanding the nature of chemical reaction is presenting the principle of element conservation as 'a set of rules that create a first degree of order in the field of chemical reactions by subjecting them to rigid conditions' (De Vos \& Verdonk 1987, p.1011). The copper cycle experiment is used to demonstrate that reactants and reaction products are related each other (Umans \& De Vos 1982). The cycle starts and ends with shiny copper, which most students are able to recognize. To find an explanation of how the copper manages to pass through the cycle, students are ready to accept the idea of copper atoms as something that safeguards the identity of copper. So, a distinction between copper as a substance and copper as an element is made. In concluding words, W. De Vos and A.H. Verdonk point at another possible approach: to describe the copper cycle phenomenon and define an element concept without any reference to molecules or atoms.

H.H. Ten Voorde (1990) proposed an even more radical approach to push students' naive ideas toward basic chemistry concepts. Students are allowed to give names to the substances they work with, the reactions and their products, and change the names when a new level of understanding is achieved. Attention is paid to the development of the concept of substance from the 'material' through the 'individual substance' to the 'chemical substance'. The teaching strategy begins with making 13-14-year-olds familiar with the classical descriptive chemistry and aims to build their concept of chemical element at first exclusively at macro level - without references to any particles. Apparently, the strategy implies the idea of element cycle as a means of structuring the available knowledge regarding chains of reactions, making it possible to combine the names of 'composing substances' (oxygen, hydrogen, magnesium, etc.) into the name of the 'composed substance'. 'This implies the general rule of conservation of chemical elements. Instead of describing a chemical reaction 
as the disappearance of substance(s) and the appearance of other substances, a chemical reaction may also be considered as a rearrangement of elements and described according to it' (Ten Voorde 1990, p.98). To merge students' concept of chemical element with the particulate model of matter, this approach considers the quantitative aspects of chemical reactions (mass and volume) and introduces what the authors called 'chemical atom'. Then, through the context of empirical physics, the latter is transformed into atom as a physical reality.

The two approaches above share the aim of building primary chemical concepts through modeling. Another common feature is that they are explicitly based on the concept of chemical element which should be constructed on both levels - macro and micro.

\section{3 'Introduction to chemistry' for 6-7 grades}

\subsection{Basic substance as a link between macro observations and micro models}

Novices who start learning chemistry immediately face such important and closely interrelated concepts as substance, chemical reaction, and chemical element (De Vos, Van Berkel \& Verdonk 1994). These primary concepts should be developed together to provide a solid basis for other chemical concepts such as composition, chemical formula, compound, etc. In the best case, the role of the concept of chemical element in introductory courses is limited to the element conservation principle and may be illustrated by performing the copper cycle or a similar experiment. However, this principle is only a tip of the iceberg, the endpoint of the development of the concept of chemical element through centuries (e.g. Siegfried 2002; Hendry 2012). It is clear that this concept (1) functions at all three levels of thinking of modern chemists; (2) bridges macro and micro by determining the way to interpret macro observations with micro models; (3) takes different meanings in different contexts: a basic substance, a simple substance, and an elemental atom (Schwarz 2007, Paneth 2003/1962; Scerri 2009; Hendry 2012; Ghibaudi, Regis \& Roletto 2013). The last two meanings prevail in contemporary chemistry standards, syllabi, and textbooks ${ }^{1}$. However the first - the original but still in use - meaning of the concept of chemical element as a basic substance which survives chemical reactions is hidden so deeply in traditional instruction that majority of students cannot grasp it properly. We consider this abstract 'transcendental' in Paneth's term and obvious to all chemists - meaning as a cornerstone of our introductory course because (1) it can be built by students through the discovery and exploration of elements cycles; (2) it can serve as an analytical tool to explore the classical field of school chemistry and find its recognizable patterns; (3) it allows further development towards atoms as units of element.

\footnotetext{
${ }^{1}$ For the definitions of the concept of chemical element in modern textbooks see E. Ghibaudi et al (2013).
} 


\subsection{The psychological framework}

Designing our course was a part of a big long-term research project of Developmental Instruction that was founded by the Russian psychologists D.B. Elkonin and V.V. Davydov in 1958. This project is based on the Activity Theory as extended by P.I. Galperin (1992) and V.V. Davydov (2008/1986) and focuses on the psychological basis of curriculum. ${ }^{2}$

Chemistry is considered as a kind of human activity aiming at the production of desired substances by combining the available chemicals (cf. Van Berkel, Pilot \& Bulte 2009; Meijer, Bulte \& Pilot 2009; Van Aalsvoort 2004; Talanquer 2013, etc.). The basic chemical concepts have originated and developed to serve the needs of this practice. The main function of these concepts is to plan the sequence of actions and predict the results 3 (cf. Taber 2010). We assume that (a) the context in which the concept of chemical element works as a planning tool is a problem of preparation of a certain substance from other chemicals; (b) to learn the main functions of the concept students should be allowed to plan the experiments. Thus, the problem of preparation of a certain substance from other chemicals becomes a template of the entire course.

Our students learn certain actions, while the corresponding concepts are considered as their derivatives (see examples in Table 1).

Table 1. Primary actions for some chemistry concepts (introductory course for 6-7 grades)

\begin{tabular}{|c|c|c|}
\hline Concept & $\begin{array}{l}\text { Actions (in question } \\
\text { form) }\end{array}$ & Execution \\
\hline $\begin{array}{l}\text { Chemical } \\
\text { reaction }\end{array}$ & $\begin{array}{l}\text { Is this change chemical or } \\
\text { not? - How to verify it? }\end{array}$ & $\begin{array}{l}\text { To prove a statement, students have to perform a } \\
\text { simple hands-on experiment to verify that they } \\
\text { really have obtained a new substance. }\end{array}$ \\
\hline Substance & $\begin{array}{l}\text { - Are these substances the } \\
\text { same or different? - How to } \\
\text { prove it? }\end{array}$ & $\begin{array}{l}\text { - At the very beginning, students rely only on } \\
\text { visible properties of the substance. Gradually, } \\
\text { they learn to test other properties such as } \\
\text { solubility in water, ability to react with certain } \\
\text { substances to form particular products, belonging } \\
\text { to a certain element cycle, etc. All tests are simple } \\
\text { hands-on experiments. } \\
\text { - Students learn common ways to make a } \\
\text { substance 'disappear' through dissolving, } \\
\text { evaporation, etc. and 'reappear' through } \\
\text { crystallization, condensation, etc. }\end{array}$ \\
\hline $\begin{array}{l}\text { Particles of a } \\
\text { substance } \\
\text { (molecules) }\end{array}$ & $\begin{array}{l}\text { - Are these particles the same } \\
\text { or different? - How to verify } \\
\text { your guess? } \\
\text { - Do these particles stay } \\
\text { together or move separately? } \\
\text { - How to check your } \\
\text { statement? }\end{array}$ & $\begin{array}{l}\text { Students interpret various physical and chemical } \\
\text { changes in their macro observations by drawing } \\
\text { micro diagrams involving multiple particles. The } \\
\text { adequacy of these diagrams is subject to } \\
\text { discussion and further testing. }\end{array}$ \\
\hline
\end{tabular}

We assume a layered structure of the primary concepts where the layers are represented by the models, each in its own context (cf. De Vos \& Pilot 2001; Taber 2010). The formation of

\footnotetext{
2 From the Western tradition, we can mention the work by B. Van Berkel, A. Pilot and A.M.W. Bulte (2009) that specifies 'philosophical and pedagogical substructures' of the curriculum. It is interesting to note that different approaches often come to similar conclusions about the dominant educational practice and possible ways of improving it.

${ }^{3}$ Note that explanation of phenomena is of secondary importance in our approach.
} 
such a structure implies an evolution of the action itself, while the concept works as a guide. This is accompanied by the evolution of the cultural-historical context in which the action is necessary. This set of models should be built with students through reconstruction of the development of the related context and corresponding action. Every new step of action development works as a driving force for the co-evolution of students' symbolic means and related conceptions. So, there is a sequence of intermediate conceptions, symbols, and terms that allow students to plan and perform their actions with substances. 4

Our teaching method is built on the Guided Discovery Approach (De Vos \& Verdonk, 1985, 1987; Ten Voorde, 1990). The main difference is that since the very beginning, students' testable ideas - both correct and incorrect - are collected to plan simple experiments to test every one of them. Students actively participate in the planning; they also perform the experiment and make a verdict about each guess. As a result, students make new observations and ask new questions, thus starting a new guess-and-test cycle. This open-ended method forces us to replace the traditional textbook with a collection of small essays. These essays present the cultural context (since ancient times) in which certain chemical problems and techniques have become significant, as well as describe goals, problems, substances, and reactions. However, the texts don't include definitions of concepts, chemical formulas, or chemical equations. All essays are descriptive rather than explanatory, and are not necessarily connected to each other.

\subsection{The structure of the course}

Upon the aforementioned principles, we have developed a local instruction theory within the educational design research framework (Collins, Joseph \& Bielaczyc 2004; Van den Akker, Gravemeijer, McKenney \& Nieveen 2006).

The course can tentatively be divided into three stages: (a) introductory - for building prerequisite conceptions about substances and their changes; (b) core - for building the concept of element as a basic substance; (c) extension - for mastering the concept by exploring the field of descriptive chemistry, including introduction of the concept of atom (see Table 2).

We have conducted three long-term macro-cycles of our design research experiment in 67 grades (Vysotskaya \& Rekhtman 2001, 2008, 2009, 2010, 2012; Vysotskaya, Rekhtman \& Khrebtova 2013). These include: (A) a 1-year course 5 for 7-graders (2 classrooms per year since 1997, network of schools since 2001); (B) a 2-year course ${ }^{6}$ starting at the 6th grade (network of schools since 2003); (C) 1-year course with historical texts for 7-graders (4 classrooms in 2 schools since 2010). After the introductory course, all students proceeded with a regular course of chemistry (8-11 grades) adjusted to take over from the introductory

\footnotetext{
${ }^{4}$ These intermediate conceptions may be different from modern ones; however, we consider them as necessary precursors to the scientific concepts, or 'useful stepping stones' in M. Wiser \& C.L. Smith's words (2008) (compare also to Johnson 1998; Johnson \& Tymms 2011; Duschl, Schweingruber \& Shouse 2007).

52 class-hours per week, 68 hours total.

${ }^{6} 2$ class-hours per week, 68 hours per year.
} 
course. The outcomes were compared to the expected outcomes in terms of understanding, engagement, progress, motivation, etc.

Table 2. 'Introduction to chemistry': course for 6-7 grades. Overview.

\begin{tabular}{ll}
\hline Parts & Units \\
\hline A. Introductory & 1.1 Magic vs. Craft - chemical and non-chemical changes \\
& 1.2 Basic particle model - modeling physical and chemical changes (including \\
& separation of mixtures) at the micro level \\
\hline B. Core & 1.3 The copper cycle - reactions are reproducible and predictable \\
& 1.4 Rust and its cycle \\
& pattern of displacement \\
\hline C. Extension & 1.6 Malachite (optional) - how to study composition: elemental formula \\
& patterns of reactions \\
& 2.1-2 Patterns of reactions. Salts - exchange reactions \\
& 2.3-4 Electrolysis - ions and electrons in chemical reactions \\
& 2.5-6 Oxidation-reduction (optional) - oxygen, chlorine, nitric and sulfuric \\
acids as common oxidants; hydrogen and coal as common reductants & 2.7 Carbon cycle (optional) - sugars, hydrocarbons, etc. \\
& 2.8 Atoms, chemical formulas \\
\hline
\end{tabular}

Here we briefly describe the first year of instruction. The first part is designed to make an impression of what chemistry is about and how changes of matter can be understood. As a warm-up, students are given unlabeled chemicals and are asked to reproduce some simple and well-known 'magic tricks' such as 'turning water into wine, then into milk'8. As a result, students recognize the value of (a) having a correct recipe; (b) making records of their trials; (c) labeling flasks with chemicals. In order to organize their journaling, students create 'nametags' using the perceived properties of substances, such as 'colorless liquid', 'black powder', etc. This kind of notation is used for the description of actions with chemicals (see Figures 2-4).

Several questions suggest themselves as the students observe how one substance 'disappears' and another one 'appears'. The students explore the problem by reading small essays about production of some socially important substances such as salt, soda, etc., and reproduce some key manipulations, such as evaporation, crystallization, condensation, etc., in the lab settings. In order to understand these simple physical changes and make the results predictable, the students utilize the Basic Particle Model9. Switching back to chemical changes, students build the simplest micro model of chemical reactions ${ }^{10}$ and use it to interpret the reactions they have performed or read about (Figure 1).

\footnotetext{
${ }^{7}$ The names of the units are for teacher's use only. The first digit of the unit number specifies the year of instruction.

8 Variants: 'into milk, then soda', etc.

${ }^{9}$ Building the BPM with students takes more time that we can spend in a 1-year course (Vysotskaya, Rekhtman 2009).

${ }^{10}$ We believe that the potential of the simplest particle model of chemical reaction is greatly underestimated by educators and researchers (cf. Eilks 2013; Papageorgiou 2013), at least when the learning process is based on iterative cycles of model building activity.
} 


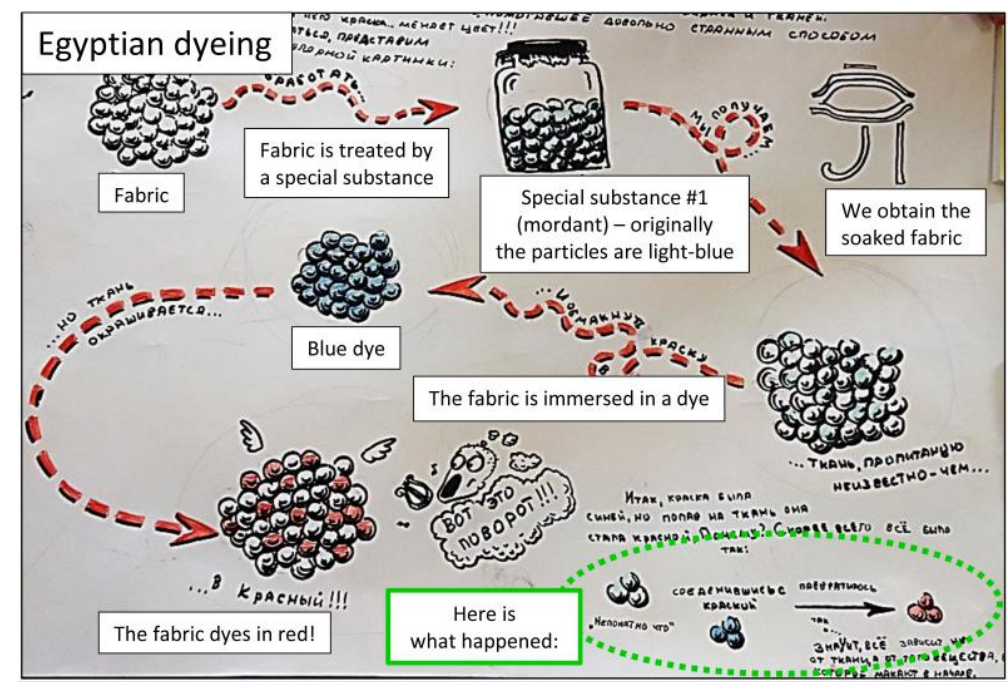

Figure 1. Project made by two 6-graders interprets a text about Egyptian technique of dyeing through micro diagrams.

The core part of the course aims at discovering for students that there is something that survives chemical transformations. At first, the students should build a chain of reactions that forms a cycle. The students work in small groups, and each group experiments with one of the 'unknown' substances (in fact, these are copper (II) compounds). The first cycle includes only copper oxide and hydroxide in powder form, and chloride and sulfate in aquatic solutions. As 'assistant' substances, as the students call them, two corresponding acids and an alkali are used. A class-wide discussion is set up to choose the names for these substances ${ }^{11}$. In order to merge the results collected from all groups into a single chain of reactions, it has been determined how many substances there really is. To find out whether similarly looking substances are the same or different, the students plan and carry out simple experiments that test some properties of these substances. Two similarly looking solutions may be evaporated, and the solids are compared visually; two precipitates can be filtrated, dried, and compared; reactions with 'assistants' are tried, etc. As a result of this activity, a cycle of reactions is built (Figure 2).

${ }^{11}$ Often, the name reflects the function of the substance in a known set of reaction; for example, an acid might be called 'solvent' or 'dissolver'. 


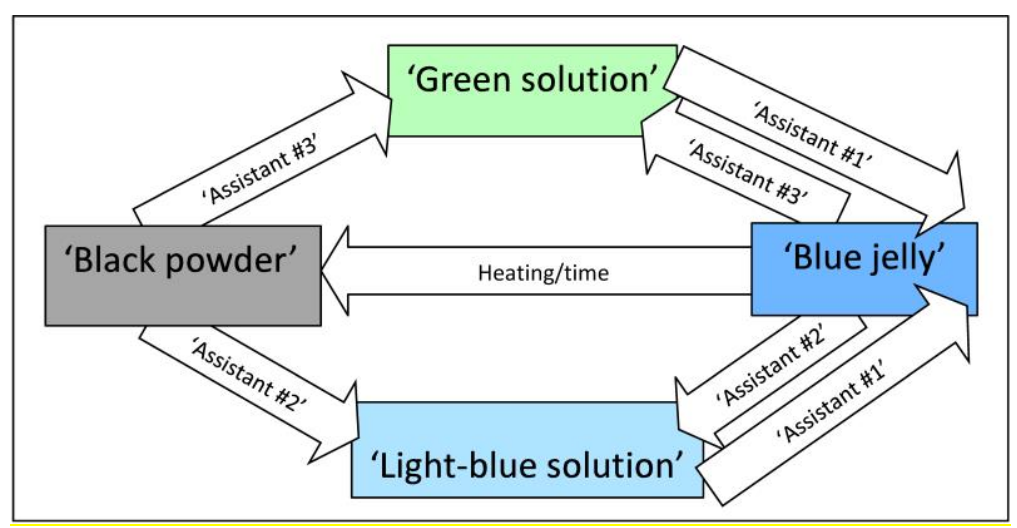

Figure 2. The first (copper) cycle as assembled by students (6 grade). The 'assistants' are: $\# 1$ - alkali, \#2 - sulfuric acid, \#3 - hydrochloric acid, all - in aquatic solutions. Note that students don't know these names or formulas yet.

Then, students use this cycle as a planning tool to solve some experimental tasks, such as how to prepare three other substances from the cycle using just one, or how to distinguish three colorless liquids in unlabeled flasks using only one given substance from the cycle. Students also try to find the genuine 'green solution' among three similarly looking unlabeled substances. Solving this task shows that there are cycles different from the one they have just learned. So, the students find it useful to label the flasks with all substances from the first cycle with a special sign - students make a class-wide agreement about the sign - to distinguish them from similarly looking chemicals from other cycles. The same sign is used to mark the particles of all substances from this cycle on the micro diagrams of reactions.

Next, the students explore the iron cycle. They begin with turning iron into rust and studying how rust reacts with the 'assistant substances', what are the products, etc. As a result, students build a chain of reaction of iron and rust (Figure 3, the bottom part). They try to use the 'Blue solution' from the first cycle as a new 'assistant' and obtain a substance that many students perceive as rust. Sorting out this situation is the next 'big problem' of the course. A careful examination of the products is planned during a class-wide discussion and carried out in small groups of students. The results are presented in front of the class. The conclusions are: (a) the 'Brown powder' is not rust; (b) it turns into the 'Black powder' from the first cycle; (c) the solution, which is the second product of this reaction, can be turned into rust (Figures 3, 4). 


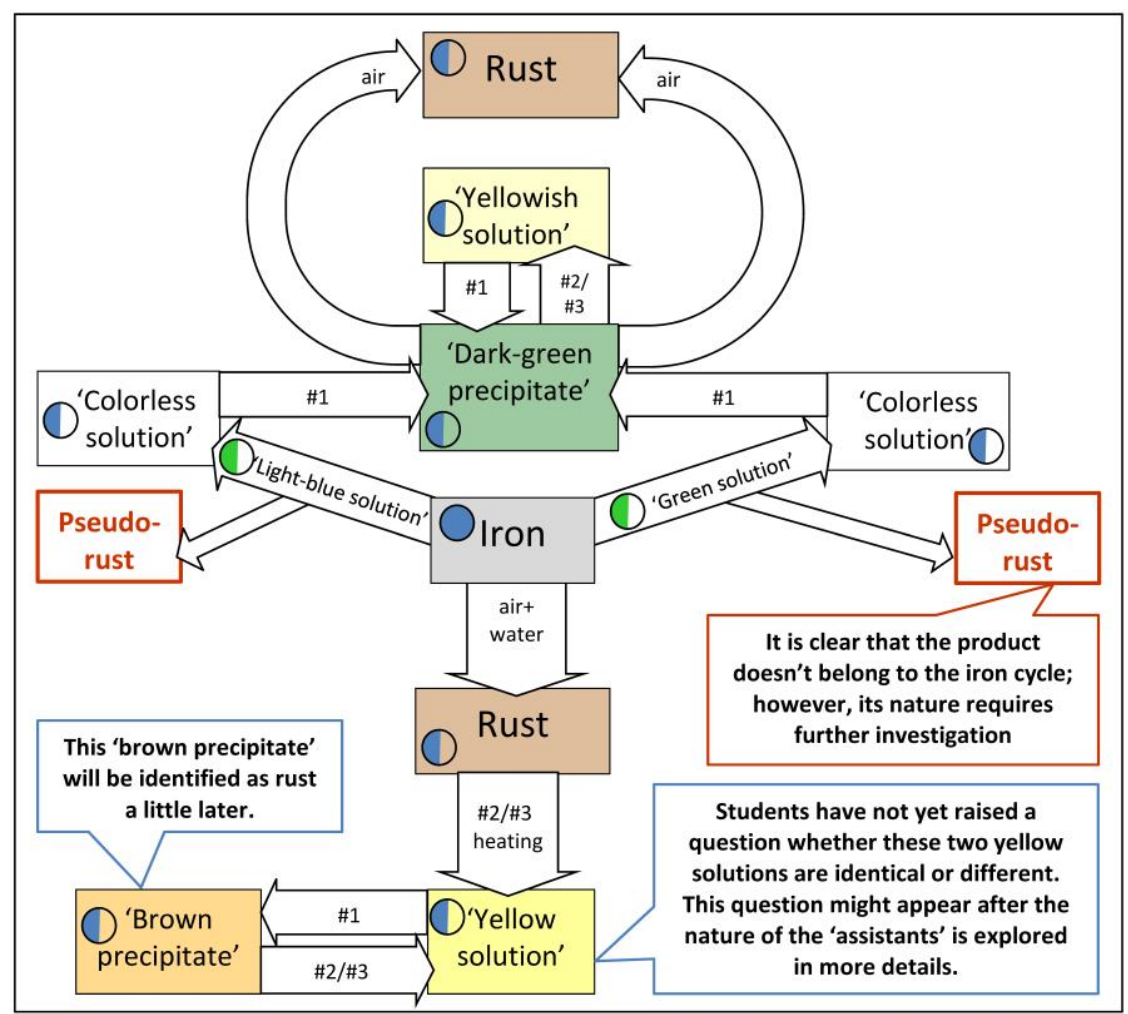

Figure 3. Iron cycle as assembled by the students (6 grade); the 'assistants' are the same as in Fig.2. The blue half-circle indicates substances belonging to the iron cycle; iron is already labelled as a simple substance, but this is not necessary at this point. The green half-circle indicates substances belonging to the first cycle.

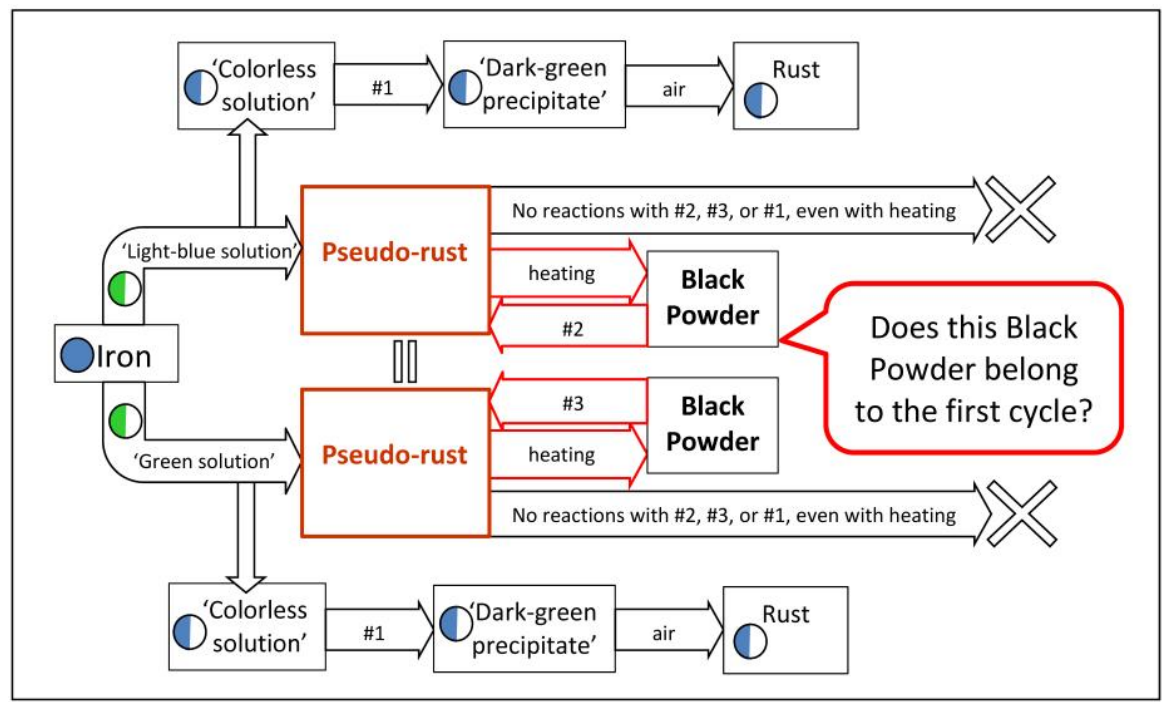

Figure 4. Study of pseudo-rust, which is the product of reactions of iron with the solutions from the first cycle (i.e., copper salts). This schema has been drawn by collaborative efforts of several small groups of 6-graders. Obtaining a black powder by heating leads students to the main question: Does this substance belong to the first cycle? At first, students answered negatively mostly because the heating time was insufficient, and the teacher's help was requested. With the corrected experimental technique, the answer is changed to positive, and the new substance is identified with the 'Black powder' from the first cycle. Later, this experience allows students to raise a reasonable question: Why do we obtain copper (recognized in pseudo-rust) back again after adding a 'dissolver' (acid)? It leads to a meaningful discussion and micro-modeling of this reaction: it is essential to realize that it occurs on the surface to understand its features and limitations. 
While modeling the relationship between the two cycles, the students choose between two options: (1) combine the cycles into a 'Big Cycle'; (2) keep the cycles separate. This becomes a topic for another discussion. Next, we are ready to ask about how substances (i.e. their particles) 'know' which product each of them should turn into. At this point, students easily accept (almost suggest) the idea of an element as a 'basic substance'. They interpret it on the micro level as a 'part' of every particle of a substance that determines the cycle to which the substance belongs. This transition generates a set of important questions: (a) What is an element - iron or rust? - The Table of Elements shows it is iron. (b) What makes substances (i.e. their particles) different within one cycle? - Different substances have different 'parts' inside their particles even if we don't know exactly what they are. (c) How is the ironsubstance different from other substances from the iron cycle? - It is 'simple', meaning there are no other elements inside the iron particles, etc. Some of these questions are asked (and answered, too) by the students themselves, some - by the teacher. Next comes the question about the element hiding in the first cycle. If the students have no clue, they are given a small text about copper and its compounds, such as blue vitriol and malachite. Then, the students repeat the experiments to turn a piece of metallic copper into blue vitriol and explore its reactions with the 'assistants' (Figure 5). By now, students are able to recognize the reactions from the first cycle and identify the 'Brown powder' as copper. As a result, copper is included into the first cycle as a simple substance, followed by the revision of the cycle.

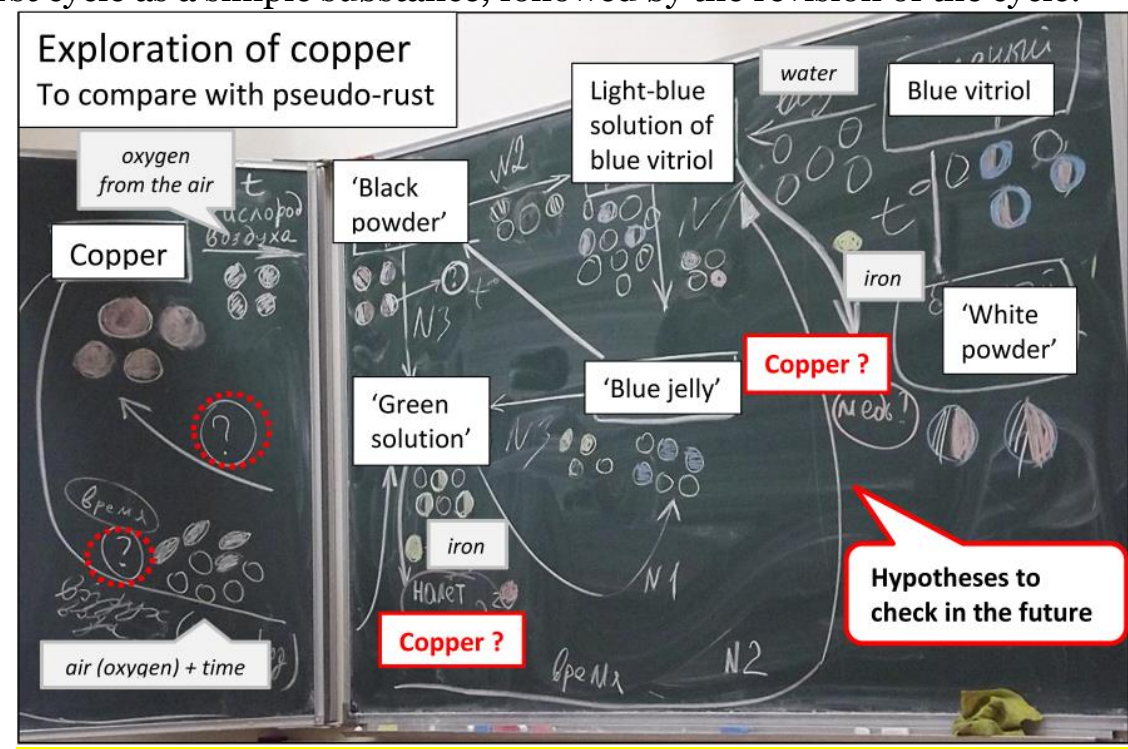

Figure 5. Exploration of copper: the summary on the blackboard, 6 grade.

As a result, the model consisting of two linked cycles is accepted as the most adequate and useful for understanding of the reactions. Discovery of the parity between the reagents in reaction opens a new field for exploration, namely, what elements form the other 'assistants'. This leads to identification of hydrogen as a common part of acids, followed by familiarization with some common metals ( $\mathrm{Zn}, \mathrm{Mg}$, etc.), another revision of the copper and iron cycles, construction of the activity series, formulation of the ideas about the composition of alkali, etc. (Figures 6-9). 


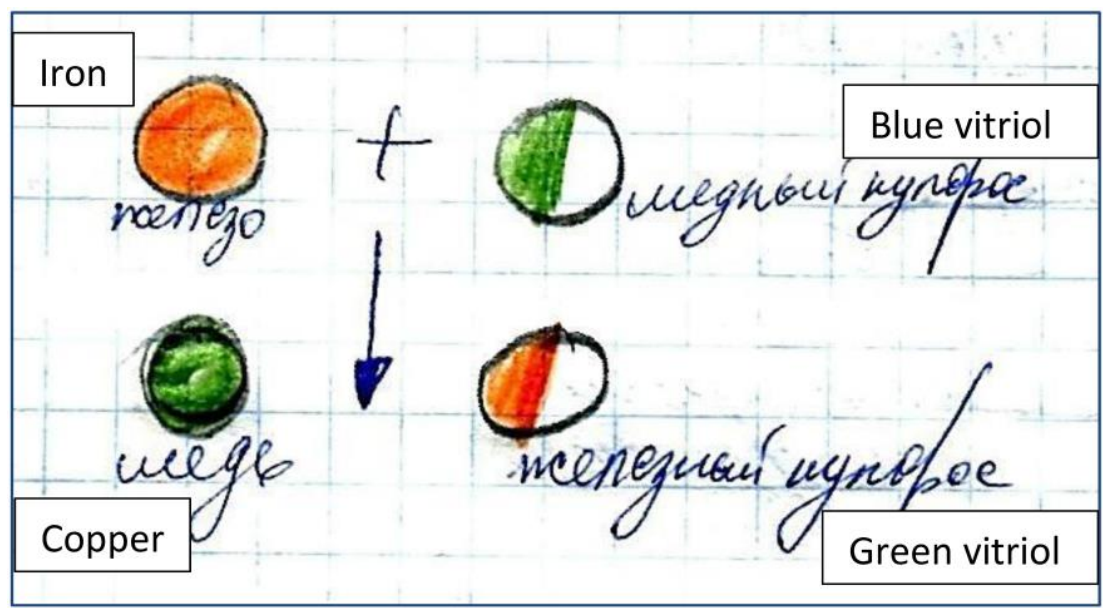

Figure 6. Pattern of displacement reaction between iron and blue vitriol, 6 grade.

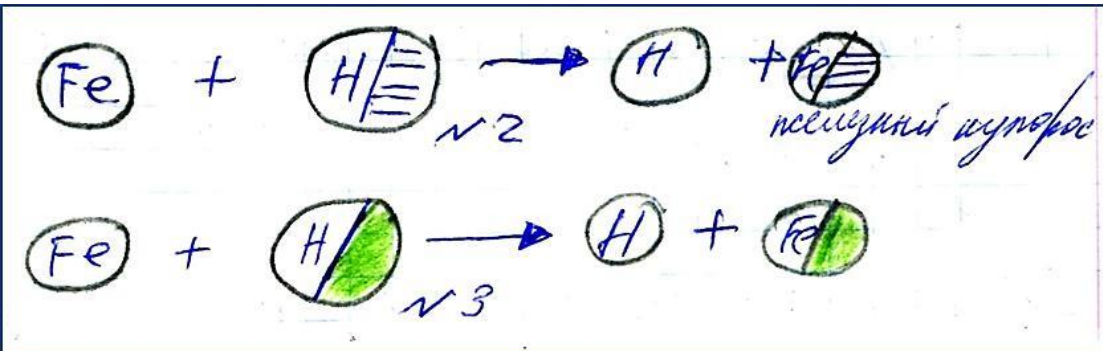

Figure 7. Patterns of reactions between iron and some 'assistants' (acids), 6 grade.

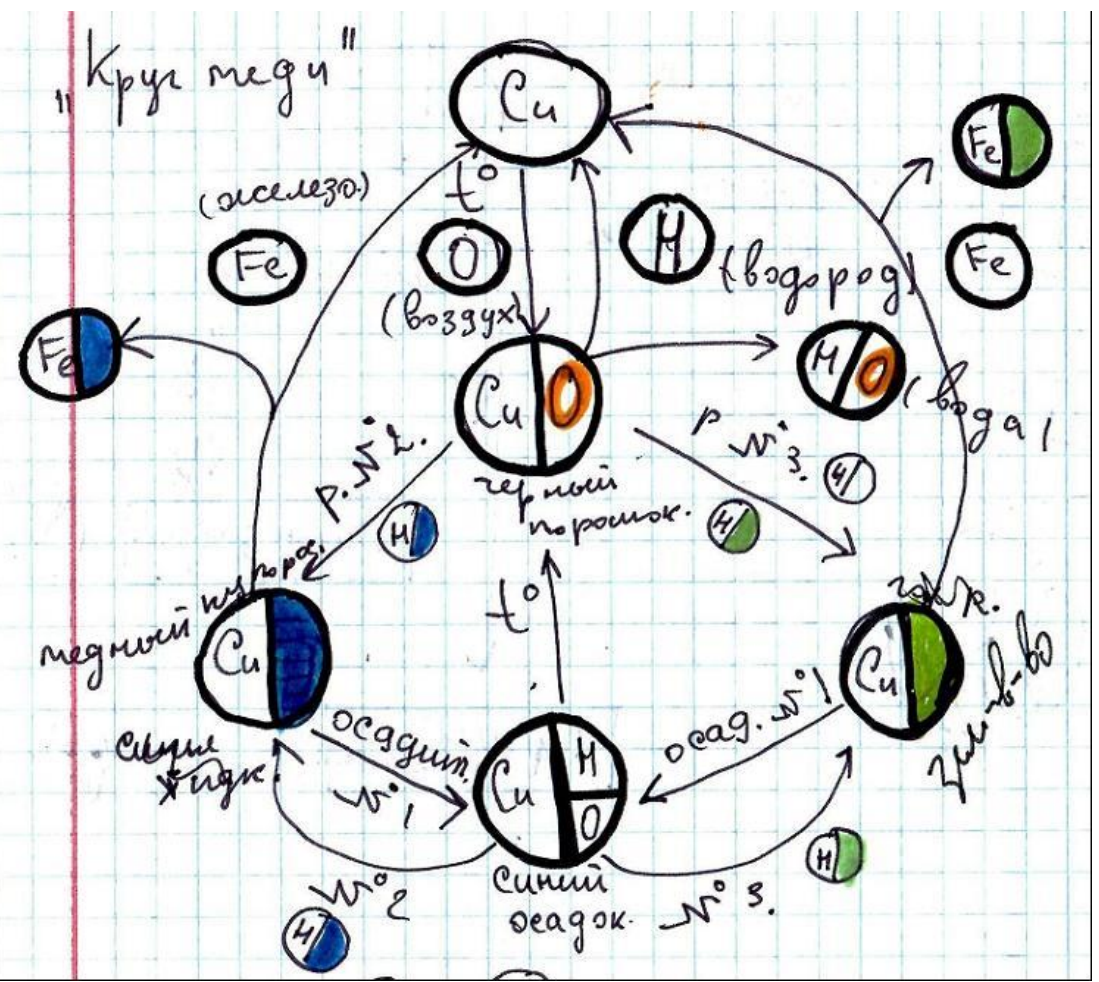

Figure 8. The Copper cycle after the major revision, 6 grade. The 'Black powder' is already identified as copper oxide $[\mathrm{Cu}, \mathrm{O}]$; 'Blue jelly' - as [Cu, O, H]; 'Light-blue solution' - as blue vitriol solution; 'assistant \#2' - as a 'dissolver' that has vitriol, too; water - as [H, O], etc. 


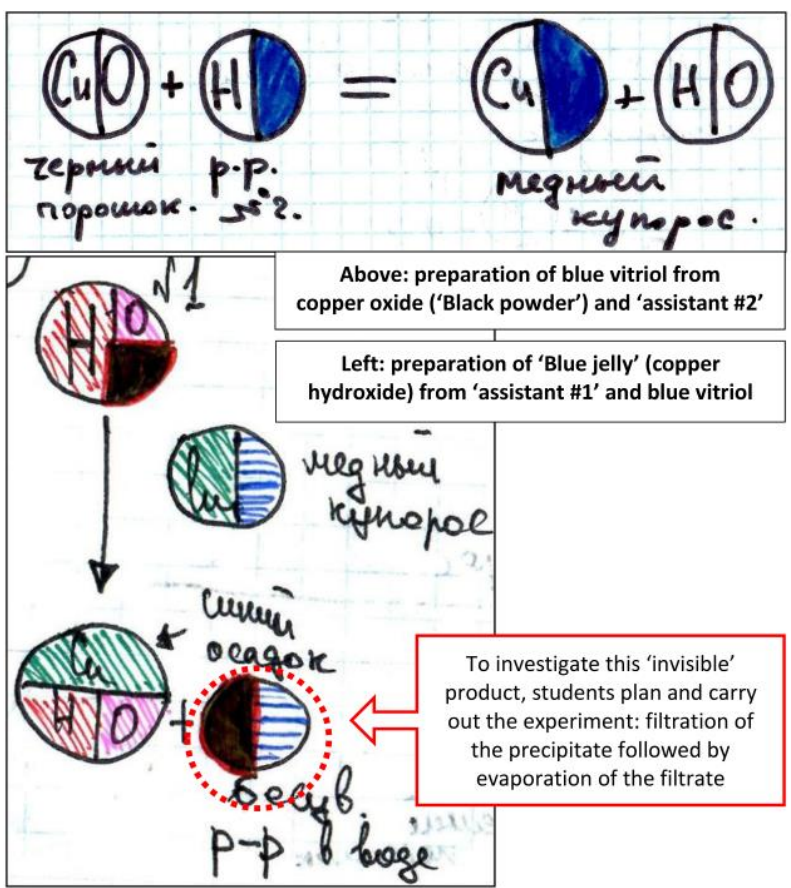

Figure 9. Patterns of reactions for the copper cycle (6 grade). By this point, students consider the conservation of elements in chemical reactions as self-evident, so they are able to suppose that in addition to the well-known and visible product, the second - 'invisible' - product forms in the reaction.

The goal of the third part of the course is migration of the students' conceptions about elements, compounds, composition, and reactions toward the regular ones. The 'Malachite' unit provides an opportunity for students to apply their new thinking tool - the concept of element as a basic substance - to the study of composition of malachite. This work includes planning experiments with malachite, examination of the products, collection and identification of the gas, and building patterns of the reactions. Thus, students construct the elemental formula of malachite $[\mathrm{Cu}, \mathrm{C}, \mathrm{O}, \mathrm{H}]$ as a summary of its transformations and look for a way to prepare it (Figure 10).

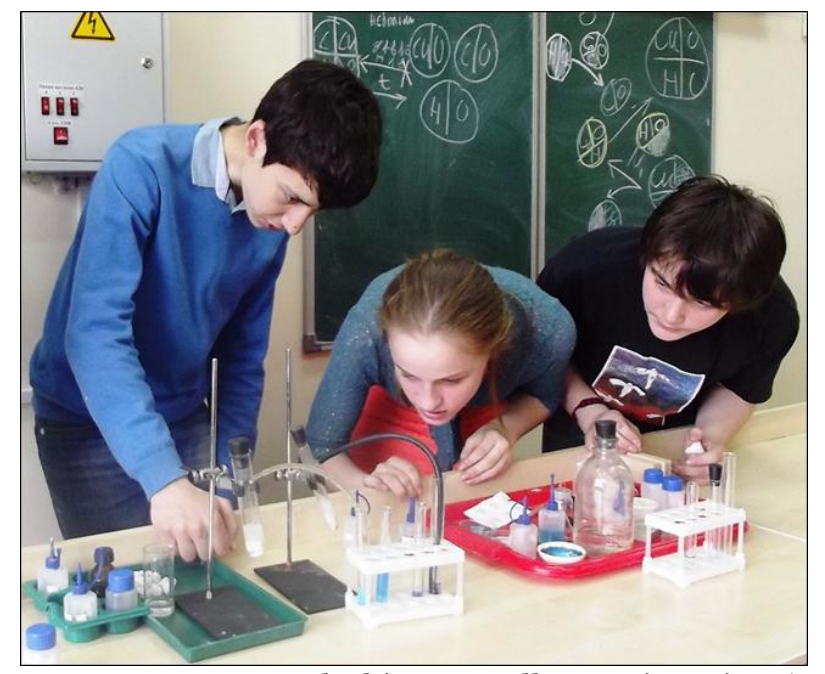

Figure 1o. Looking for a way to prepare malachite: a small group in action. 'Is there something going on?' 7 grade, 1 -year course. 
The unit called 'Acids, bases. Neutralization' includes exploration of common properties and composition of acids and bases in more details. The patterns of the reactions include exchange reactions and their 'invisible' products. The difference between acids is studied, and cycles of transformation of common nonmetals (S, P, C) and of some active metals (Na, $\mathrm{Mg}$ ) are constructed. Salts are defined as a particular type of compounds. This completes the first year of teaching (Figure 11).

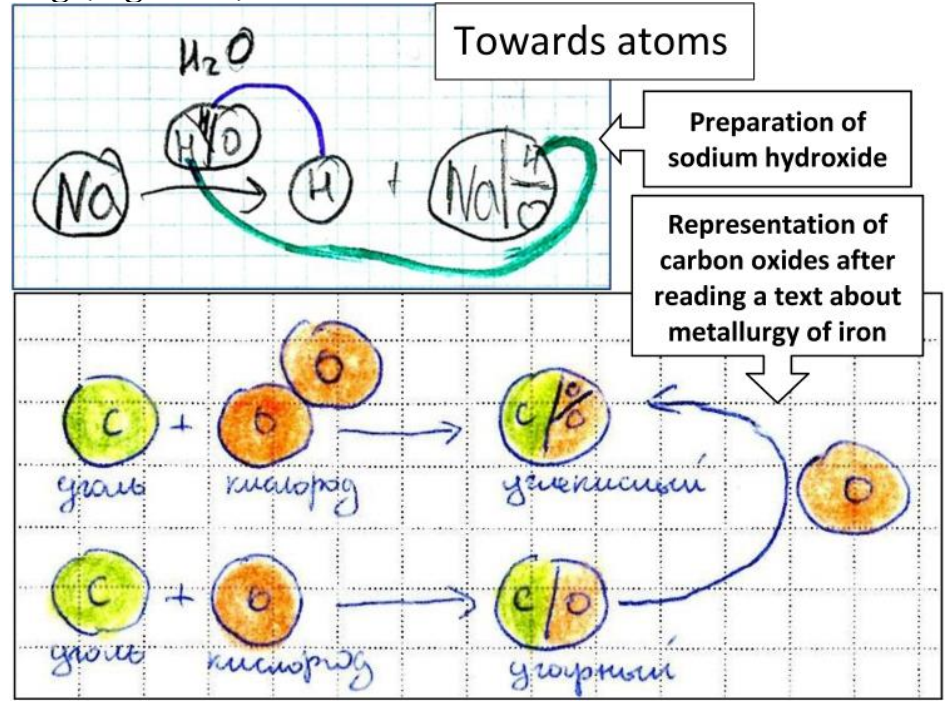

Figure 11. From elements to atoms: patterns of reactions, 6 grade.

At this point, it is already possible to make a transition to a regular chemistry course where atoms are considered as bearers of element properties at the micro level. However, the best results can be obtained if the concept of element with the related conceptions continues to develop as shown in Table 2 (Zuckerman \& Venger 2010; Vysotskaya, Rekhtman, \& Khrebtova, 2013).

\section{Effects and benefits}

Building the notion of element cycle along with students and application of it as a tool to the study of composition of the classical set of chemicals brings various benefits. Below is the summary collected from our 15-year-long experience (Vysotskaya \& Rekhtman 2001, 2008, 2009, 2010, 2012; Vysotskaya, Rekhtman \& Khrebtova 2013).

A. An active role in learning is very attractive to 11-13-year-olds. A student of this age definitely enjoyed being a subject of cognitive activity whereby he or she becomes a 'master of the world of chemicals'. Our students constantly point at chemistry as their favorite subject. Their motivation toward the classes, engagement in classroom activity, the level of homework completion, overall progress and understanding are excellent (given no student selection), especially for younger grades. Questionnaires show the average of about 90 points out of 100 for students' interest toward chemistry for each of the two years of learning the introductory course, while after transition to the regular course that is mandatory for students, the average is about 74 points (Zuckerman \& Venger 2010). 
B. Constructing intermediate conceptions, models, and the supporting symbolic system with active students' participation allows students to apply these tools easily and modify, revise, or reconstruct them according to experiment results. Our students can retool and extend their own understanding for new problems. Transition to the regular chemistry course is smooth and successful when the teacher allows students to take an active part in learning, shows the origin of well-known rules, and helps students to test the boundaries. The students easily master such topics as structure of atoms, chemical bonding, chemical formulas, equations, etc. There are no problems with these really difficult subjects that ordinarily take a lot of time and efforts. Many of our students have kept their interest to various parts of chemistry and choose the available chemistry electives in high school.

C. The tentative nature of the intermediate models that students build in the classroom often stimulates them to wander beyond their current assignment. As a result of this spontaneous activity, we observe regular appearance of sensible 'chemical' questions and reasonable guesses related to their everyday life. Some questions suggest anticipation of the next learning topics. We consider this as an evidence of assimilation of a new point of view by the students. On the other hand, we treat these questions as short-term learning goals, so we try to proceed in the direction chosen by the students every time we have a chance. In a search for an answer to their own question about the 'actual composition' of known substances and explanation of their properties, a noticeable part of the students go as far as turning to the regular chemistry textbooks (we usually observe this in the middle of the first year of teaching). Thus, our students arrive at the regular chemistry course with meaningful questions about atoms, bonds, regular formulas, subscripts, and causes of reactions, as well as about how this knowledge has become available.

D. Our introductory course greatly stimulates the growth of students' learning initiative. This stimulates the development of their learning independence, as is shown by our project partners G.A. Zuckerman and A.L. Venger's (2010) in their longitudinal study. In particular, their work indicates that our 'Introduction to chemistry' was the only course beyond elementary school where students' learning initiative has increased significantly for all groups of students. Even after transitioning to the regular chemistry course, the majority of students (62\%) have kept a high level of learning initiative (more than 75 points out of 100), and only $11 \%$ show a low level (less than 49 out of 100).

E. Through the familiarization with ancient technologies and testing the principles of them in lab settings, the students realize the important role of chemistry and chemical technology in human history and culture, understand the value and significance of chemical knowledge in particular and of scientific knowledge in general, and accept the reproducibility of experiments and the testability of guesses as significant criteria of scientific method. The question 'How did people come to know it?' is what we often hear, especially after the regular chemistry course takes over. 
At the end of our introductory course, the students have learned to think about composition of the chemicals before they try any reaction with them. We believe that this alone is a big step toward the practical chemical literacy. 


\section{References}

Barke, H.-D., Harsch, G. \& Schmid, S. (2012). Essentials of Chemical Education. Springer.

Barke, H.-D., Hazari. A. \& Yitbarek, S. (Eds.). (2009). Misconceptions in Chemistry. Springer.

Collins, A., Joseph, D. \& Bielaczyc, K. (2004). Design Research: Theoretical and Methodological Issues. The Journal of the Learning Sciences, 13(1), 15-42.

Davidowitz, B. \& Chittleborough, G. (2009). Linking the Macroscopic and Sub-microscopic Levels: Diagrams. In Gilbert, J.K. \& Treagust, D. (Eds.). Multiple representations in chemical education. Models and modeling in science education 4, Springer (ch.8, 169-191).

Davydov, V.V. (2008/1986). Problems of developmental instruction: a theoretical and experimental psychological study. Nova Science Publishers (Original published in Russian in 1986).

De Vos, W., Bulte, A. \& Pilot, A. (2002). Chemistry curricula for general education: analysis and elements of a design. In Gilbert, J.K., De Jong, O., Justi, R., Treagust, D., \& Van Driel, J.H. (Eds.). Chemical Education: Towards Research-Based Practice. Kluwer Academic Publishers (ch.5, 101124).

De Vos, W. \& Pilot, A. (2001). Acids and bases in layers: the stratal structure of an ancient topic. Journal of Chemical Education, 78 (4), 494-499.

De Vos, W., Van Berkel, B. \& Verdonk, A.H. (1994). A coherent conceptual structure of the chemistry curriculum. Journal of Chemical Education, 71 (9), 743-746.

De Vos, W. \& Verdonk, A.H. $(1985,1987)$. A new road to reactions. Part 1. Journal of Chemical Education 62 (3), 238-240. Part 2. J.Chem. Educ. 62 (8), 648-649. Part 4. J.Chem. Educ. 64 (8) 692-694. Part 5. J.Chem. Educ. 64 (12) 1010-1013.

De Vos, W., \& Verdonk, A. H. (1996). The particulate nature of matter in science education and in science. Journal of Research in Science Teaching, 33 (6), 657-664.

Devetak I. \& Glazar S.A. (Eds.). (2014). Learning with understanding in the chemistry classroom. Springer

Duschl, R.A., Schweingruber, H.A. \& Shouse, A.W. (Eds.). (2007). Taking science to school:

Learning and teaching science in grades K-8. The National Academies Press, Washington, D.C

Eilks, I. (2013). Teacher pathways through the particulate nature of matter in lower secondary school chemistry: continuous switching between different models or a coherent conceptual structure? In Tsaparlis G. \& Sevian H. (Eds.). (2013). Concepts of matter in science education. Innovations in Science Education and Technology 19, Springer (ch.10, 213-230).

Eilks, I., Witteck, T. \& Pietzner, V. (2012). The role and potential dangers of visualisation when learning about sub-microscopic explanations in chemistry education. CEPS Journal, 2(1), 125145 .

Franco, A.G. \& Taber, K.S. (2009). Secondary students' thinking about familiar phenomena: learners' explanations from a curriculum context where 'particles' is a key idea for organising teaching and learning. International Journal of Science Education 31(14), 1917-1952.

Galperin, P. I. (1992). Stage-by-stage formation as a method of psychological investigation. Journal of Russian and East European Psychology, 30(4), 60-80.

Ghibaudi, E., Regis, A. \& Roletto, E. (2013). What do chemists mean when they talk about elements? J. Chem. Educ., 9o, 1626-1631.

Gilbert, J.K., De Jong, O., Justi, R., Treagust, D., \& Van Driel, J.H. (Eds.). (2002). Chemical Education: Towards Research-Based Practice. Kluwer Academic Publishers.

Gilbert, J.K. \& Treagust, D. (Eds.). (2009). Multiple representations in chemical education. Models and modeling in science education 4 , Springer.

Gilbert, J.K. \& Treagust, D. (2009a). Introduction: macro, submicro and symbolic representations and the relationship between them: key models in chemical education. In Gilbert, J.K. \& Treagust, D. (Eds.). Multiple representations in chemical education. Models and modeling in science education 4, Springer. Pp.1-8. 
Harrison, A.G. \& Treagust, D.F. (2002). The particulate nature of matter: challenges in understanding the submicroscopic world. In Gilbert, J.K. et al. (Eds.). (2002). Chemical Education: Towards Research-Based Practice. Kluwer Academic Publishers (ch.9, 189-212)

Hendry, R.F., (2012). Elements. In Hendry, R.F., Needham, P. \& Woody, A.I. (Eds.). Philosophy of chemistry. Handbook of the philosophy of science. Vol.6. Elsevier. Pp.255-269.

Johnson, P. (1998). Progression in children's understanding of a 'basic' particle theory: a longitudinal study. International Journal of Science Education, 2O(4), 393-412.

Johnson, P. \& Papageorgiou, G. (2010). Rethinking the introduction of particle theory: A substancebased framework. Journal of Research in Science Teaching, 47(2), 130-150.

Johnson, P. \& Tymms, P. (2011). The emergence of a learning progression in middle school chemistry. Journal of Research in Science Teaching, 48(8), 849-877.

Johnstone, A. H. (2000). Teaching of chemistry: Logical or psychological? Chemical Education: Research and Practice in Europe, 1(1), 9-15.

Johnstone, A. H. (2010). You can't get there from here. Journal of Chemical Education, 87(1), 22-29.

Justi, R. \& Gilbert, J. (2002). Models and modelling in chemical education. In Gilbert, J.K. et al. Chemical Education: Towards Research-Based Practice. Kluwer Academic Publishers (ch.3, 4768).

Lijnse, P.L., Litch, P., de Vos, W. \& Waarlo, A.J. (Eds.) (1990). Relating macroscopic phenomena to microscopic particles. A central problem in secondary science education. Proceedings of a Seminar. Utrecht.

Meijer, M.R., Bulte, A.M.W. \& Pilot, A. (2009). Structure-Property Relations Between Macro and Micro Representations: Relevant Meso-levels in Authentic Tasks. In Gilbert, J.K. \& Treagust, D. (Eds.), Multiple Representations in Chemical Education. Models and Modeling in Science Education 4, Springer (ch.9, 195-213).

Nieswandt, M. (2007). Student affect and conceptual understanding in learning chemistry. Journal of Research in Science Teaching, 44(7), 908-937.

Paneth, F.A. (2003/1962). The epistemological status of the chemical concept of element. Foundations of Chemistry, 5, 113-145. The first publication in English was in British Journal for the Philosophy of Science, 13, p.1-14 (Part I), p.144-16o (Part II), 1962.

Papageorgiou, G. (2013). Can simple particle models support satisfying explanations of chemical changes for young students? In Tsaparlis G. \& Sevian H. (Eds.). (2013). Concepts of matter in science education. Innovations in Science Education and Technology 19, Springer (ch.15, 319329).

Pilot A. \& Bulte A.M.W. (Eds.). (2006). Context-based chemistry education: special issue. International Journal of Science Education, 28(9).

Scerri, E.R. (2009). The dual sense of the term "element", attempts to derive the madelung rule, and the optimal form of the periodic table, if any. International Journal of Quantum Chemistry, 109, 959-971.

Schwarz, W.H.E. (2007). Recommended questions on the road towards a scientific explanation of the periodic system of chemical elements with the help of the concepts of quantum physics. Foundations of Chemistry, 9(2), 139-188.

Siegfried, R. (2002). From elements to atoms: a history of chemical composition. American Philosophical Society, Philadelphia, PA.

Smith, C. L., Wiser, M., Anderson, C. W., \& Krajcik, J. (2006). Implications of research on children's learning for standards and assessment: A proposed learning progression for matter and atomicmolecular theory. Measurement: Interdisciplinary Research and Perspectives, 14(1\&2), 1-98.

Taber, K.S. (2001). Building the structural concepts of chemistry: some considerations from educational research. Chemistry Education: Research and Practice in Europe, 2(2), 123-158.

Taber, K.S. (2010). Straw men and false dichotomies: overcoming philosophical confusion in chemical education. Journal of Chemical Education, 87(5), 552-558. 
Talanquer, V. (2013). School chemistry: The need for transgression. Science \& Education 22, 17571773.

Ten Voorde, H.H. (1990). On teaching and learning about atoms and molecules from a van Hiele point of view. In Lijnse P.L. et al. (Eds.) Relating macroscopic phenomena to microscopic particles. A central problem in secondary science education. Utrecht. Pp.81-103.

Tsaparlis, G., Kolioulis, D. \& Pappa, E. (2010). Lower-secondary introductory chemistry course: a novel approach based on science-education theories, with emphasis on the macroscopic approach, and the delayed meaningful teaching of the concepts of molecule and atom. Chemistry Education Research and Practice, 11, 107-117.

Tsaparlis G. \& Sevian H. (Eds.). (2013). Concepts of matter in science education. Innovations in Science Education and Technology 19, Springer.

Umans, T. \& De Vos, W. (1982). An improved copper cycle experiment. Journal of Chemical Education, 59(1), 52.

Van Aalsvoort, J. (2004). Activity theory as a tool to address the problem of chemistry's lack of relevance in secondary school chemical education. International Journal of Science Education, 26 (13), 1635-1651.

Van Berkel, B., Pilot, A. \& Bulte, A.M.W. (2009). Micro-macro thinking in chemical education: why and how to escape. In Gilbert, J.K. \& Treagust, D. (Eds.). Multiple representations in chemical education. Models and modeling in science education 4, Springer (ch.2, 31-54).

Van den Akker J., Gravemeijer, K., McKenney, S., \& Nieveen, N. (Eds.) (2006). Educational design research. London: Routledge.

Van Der Valk, T., Van Driel, J.H. \& De Vos, W. (2007). Common characteristics of models in presentday scientific practice. Research in Science Education, 37, 469-488.

Vrtacnik, M., Sodja, K. \& Juriševic, M. (2014). Students' achievement in learning chemistry through the design and construction approach to laboratory activity and the relation with their prior achievements and motivation to learn. In Devetak, I. \& Glazar, S.A. (Eds.). Learning with understanding in the chemistry classroom. Springer (ch.11, 209-231).

Vysotskaya, H. \& Rekhtman, I. (2001). On the basic concepts in chemistry. Chemistry: Instruction in school, 1, 51-57 (in Russian).

Vysotskaya, H. \& Rekhtman, I. (2008). An Active-learning Environment as a Way to Co-construction of Basic Concepts of Natural Science. ISCAR Congress, September 8-13, San Diego, USA, p.22.

Vysotskaya, H. \& Rekhtman, I. (2009). Chemistry. In Vorontsov, A.B. (Ed.). Principles of developmental instruction for middle school: syllabi (approach by Elkonin and Davydov). Moscow: Vita-press, 378-409 (in Russian).

Vysotskaya, H. \& Rekhtman, I. (2010). Functional pre-concepts as a bridge between students everyday and scientific concepts. Biennial Meeting of EARLI SIG1O and SIG21. Utrecht, Netherlands, September 2-3, p.94.

Vysotskaya, H. \& Rekhtman, I. (2012). Two approaches to designing the third teaching strategy and the choice of 'basic units' in the chemistry domain. Cultural-Historical Psychology, 4, 42-54 (in Russian).

Vysotskaya, E., Rekhtman, I. \& Khrebtova, S. (2013). Activity Theory approach to the triplet relationship. In Book of Abstracts. EAPRIL 2013 Conference, p.22.

Wiser, M. \& Smith, C.L. (2008). Learning and teaching about matter in grades K-8: When should the atomic-molecular theory be introduced? In Vosniadou, S. (Ed.) International handbook of research on conceptual change. Routledge, 205-239.

Zuckerman, G.A. \& Venger, A.L. (2010). Development of learning self-dependence. M. Open Institute for Developmental Education. (In Russian). 